Biomass Energy

https://doi.or/10.52825/thwildauensp.v1i.13

(C) Authors. This work is licensed under a Creative Commons Attribution 4.0 International License

Published: 15 June 2021

\title{
Estimation of the Amount of Electrical Energy Available From the Biogas Produced in the City of Sokodé
}

Nitale M'Balikine KROU ${ }^{1[\text { https://orcid.org/0000-0001-7091-3559] }}$, Gnon BABA 2[https://orcid.org/0000-0003-0168-0362], Ogouvidé AKPAKI 1[https://orcid.org/000-0001-9816-5580]

\author{
${ }^{1}$ University of Kara, Togo \\ ${ }^{2}$ University of Lomé, Togo
}

\begin{abstract}
The purpose of this study is to estimate the amount of energy produced from biogas at the faecal sludge treatment plant in the city of Sokodé. The methodological approach consisted in producing biogas by co-digestion of faecal sludge with the fermentable fractions of solid waste then in estimating the quantity of energy available from the produced biogas. Tests of co-digestion of faecal sludge and fermentable fractions of solid waste, showed that from 2258 tons/DM of biomass in one year, $44476 \mathrm{~m} 3$ of biogas, or $29177 \mathrm{~m} 3$ of methane could be produced. The methane content, which is $65.6 \%$, is a very interesting source of energy. Several techniques for producing energy from biogas exist, one of which is the production of electricity. In this study, it is a question of making the choice of an adequate electric motor which will allow to produce electric energy from the biogas on the faecal sludge treatment plant. Thus, it was necessary to estimate the quantity of energy available from the biogas produced. To do so, it was calculated the quantity of energy that can be produced by the biogas in one year, the quantity of recoverable energy produced in a year and the quantity of energy supplied by biogas in one hour. The results showed that by 2035 , the co-digestion of fermentable solid waste and faecal sludge from the city of Sokodé, would produce $534,246 \mathrm{kWh}$. The recoverable part would be 507,534 kWh and the energy supplied is $58 \mathrm{kWh}$.
\end{abstract}

Keywords: Biomass, biogas, electrical energy, faecal sludge.

\section{Introduction}

Non-traditional biomass to be used to improve electricity production by biogas processes in Africa seems to be innovative whereas decentralized small-scale biogas units locally are used. The widespread application of big scale biogas digesters still is missed. Faecal residues of human origin fermentation usually requires addition of co-substrates such as corn or wheat to improve the feasibility, what is not adequate for Africa. Hereby, traditional biomass as straw etc. as well as bio-waste or other organic waste could be suitable.

In Togo, as in most developing countries, the amount of energy produced is less than consumption [1]. Biomass, which is the main source of energy, represents $76 \%$ of final energy consumption, with mainly wood fuels, in particular fuelwood, charcoal and certain agricultural residues. Despite the fact that energy production remains below demand, the energy supplying countries in Togo only reduce the amount over time as the demand only exacerbates. In order to fill this vacuum which continues to widen further, the use of renewable energies has become essential [2]. In this context, the production of biogas from fermentable waste is an opportunity for the diversification of energy resources and sustainable management of the environment. The production of biogas through organic 
waste and its use could increase the economic feasibility of sanitation projects through the production of electricity. The use of biogas will directly contribute to meeting the challenges of climate change and responding to Togo's current energy challenges. Indeed, biogas is a renewable fuel gas resulting from the degradation of animal or plant organic matter by microorganisms under anaerobic conditions. This gas is mainly composed of methane $\left(\mathrm{CH}_{4}\right)$ and carbon dioxide $\left(\mathrm{CO}_{2}\right)$. The energy potential of biogas results from its methane content, the lower calorific value (LCV) of which is $9.94 \mathrm{kWh} / \mathrm{Nm}$ [3]. First used for the stabilization of sludge, anaerobic digestion has advantages for today's society. Upstream, this is a relevant way to treat waste, and downstream, it is a response to the pollution problems generated by the consumption of fossil fuels and the depletion of these resources. Biogas is an interesting source of energy since, on the one hand, it comes from a renewable resource (e.g organic waste) and on the other hand, its recovery ensures a reduction in GHG emissions, methane having a power of global warming greater than carbon dioxide. Its use therefore has a double environmental advantage [3]. Biogas is usually burned to produce heat and electricity in cogeneration [4]. Thanks to the combined production of heat and electricity, energy losses could be reduced significantly [5]. The combustion of biogas in an engine or turbine produces mechanical energy called primary energy. This energy is recovered and then used as electrical energy and heat with an overall efficiency of up to $90 \%$ [6]. This technology can meet the needs of industrial applications, rural electrification, district heating and large-scale power generation. However, the water saturation of the biogas as well as the presence of $\mathrm{CO}_{2}$ and possible $\mathrm{H}_{2} \mathrm{~S}$ are likely to make the biogas corrosive. In addition, biogas contains other compounds in trace amounts such as volatile organic silicon compounds or halogenated compounds. These trace compounds present in biogas are a brake on its energy recovery. Thus, upstream of its conversion into energy, extensive treatment of the biogas is therefore essential for such an application. It will therefore be necessary to include at least a stage of condensation of the water vapor or to go through a stage of purification.

According to the principle of converting biogas into electrical energy, the biogas is burned and the energy released feeds a generator which produces electricity. Indeed, the main composition of biogas is methane. Biogas thus has chemical energy, and the electricity produced by biogas therefore comes from the conversion of this chemical energy into mechanical energy and ultimately into electricity. Feedback has shown that this conversion is done through the use of generators and turbines which convert energy from one form to another. This involves connecting the source of biogas such as the bottle containing pressurized gas or a digester to the inlet of the gas engine and then connecting the gas engine to the alternating current generator so that the shaft rotary feeds the generator with alternating current. The movement transferred to the generator produces electricity by magnetism. The generator is connected to cables that transfer electricity to a rechargeable battery for storage or directly to an electrical distribution network for consumption. Tests of co-digestion of faecal sludge with the fermentable fractions of solid waste from the city of Sokodé in Togo, showed a significant production of biogas with a proportion of more than 65 $\%$ of methane. This high proportion of methane is a source of energy that could be converted into electrical energy for lighting the Sokodé faecal sludge treatment plant. Thus, the objective of this work is to estimate the amount of energy available from the biogas produced by the co-digestion of faecal sludge and fermentable fractions of solid waste. Methane is the origin of the use of biogas as an energy source. Estimating the amount of energy produced from biogas requires prior knowledge of the Lower Calorific Value (LCV) of the methane contained in this biogas. In fact, the LCV corresponds to the combustion reaction with the formation of water in the gaseous state. The LCV of biogas is proportional to its methane content [7]. It is therefore between $10.74 \mathrm{MJ}^{-\mathrm{Nm}^{-3}}$ and $25.06 \mathrm{MJ}^{-\mathrm{Nm}^{-3}}$ for a methane content between 30 and $70 \%$ [8]. 


\section{Materials and methods}

\section{Amount of biogas and proportion of methane}

The main purpose of anaerobic digestion is the production of biogas. In this study, biogas was produced by co-digestion of faecal sludge and fermentable fractions of solid waste. The tests were carried out in digesters. The pilot digesters were connected through gas supply pipes, to inverted test tubes immersed in a beaker containing a trap solution, consisting of water saturated with $\mathrm{NaCl}$ and acid ( $5 \%$ hydrochloric acid, $20 \% \mathrm{NaCl}$ and $\mathrm{pH}=2$ ) in order to minimize the dissolution of $\mathrm{CO}_{2}$ in the biogas $[9,10]$. This aqueous trap solution makes it possible, by moving the liquid, to properly quantify the daily production of biogas. The volume of biogas is measured using a hydraulic system (liquid displacement). The gas produced at the exit of the digester passes into a graduated cylinder immersed in a liquid, which will displace the level of the liquid contained in the cylinder and thus indicate the volume of the gas produced (figure 1).

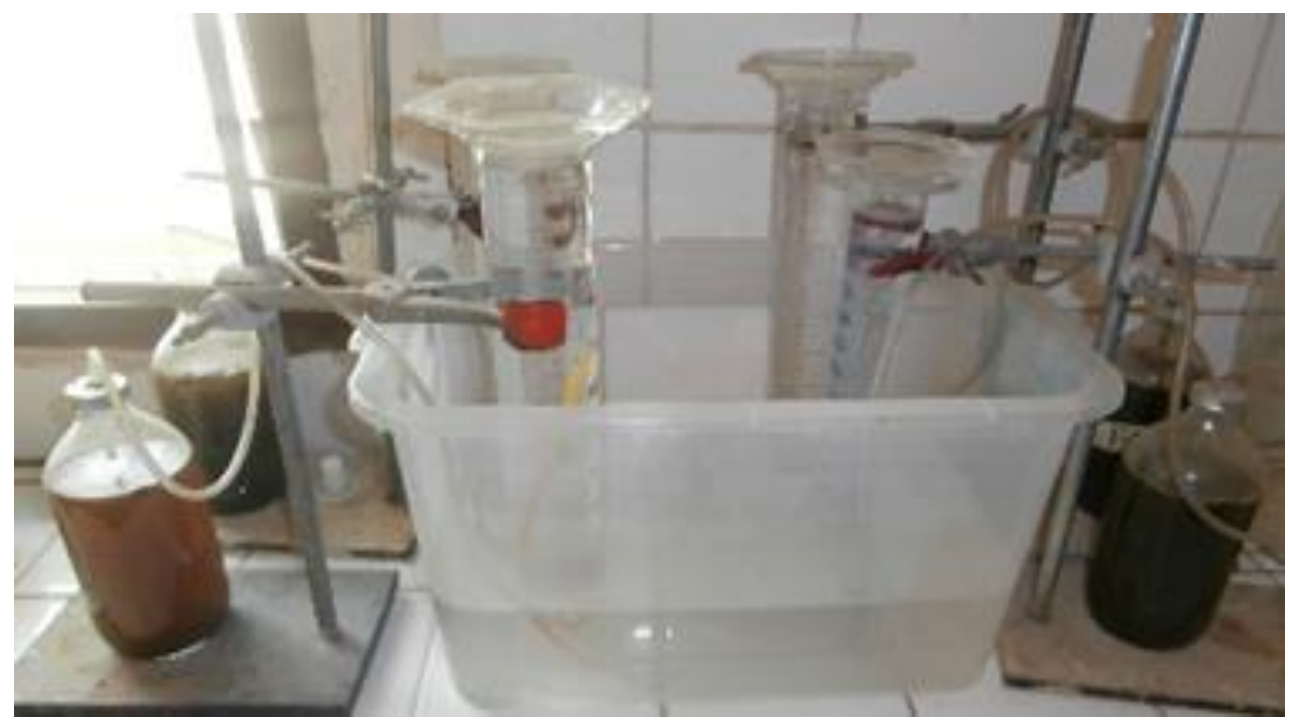

Figure 1. Biogas production device

The proportion of methane is obtained by formula 1.

$$
\% \text { methane }=\frac{\text { Quantity of methane obtained }}{\text { Total amount of biogas }}
$$

\section{Energy that can be produced by biogas in one year}

The energy produced by biogas is calculated from the Lower Calorific Value (LCV) of methane which is $9.94 \mathrm{kWh} / \mathrm{m}^{3}$ under normal temperature and pressure conditions [6]. The total energy is obtained by the formula 2 .

$$
\text { TotE }=\mathrm{LCV} \times \mathrm{V}_{\mathrm{CH} 4}
$$

\section{Recoverable energy produced in one year}

We allow $5 \%$ energy loss in order to be sure that an engine is rather overfed than underfed. The energy recoverable by an engine is therefore obtained by formula 3 .

$$
\mathrm{ER}=0.95 \times \text { TotE }
$$

\section{Calculation of the energy supplied by the biogas in one hour}

The energy supplied by biogas in one hour is obtained by formula 4 .

$$
\mathrm{ES}=\frac{\mathrm{ER}}{(365 \times 24)}
$$




\section{Results and discussion}

\section{Amount of biogas and proportion of methane}

The results of the co-digestion show that from $1 \mathrm{~L}$ of co-substrate in 42 days of co-digestion, an average production of $4 \mathrm{~L} / \mathrm{g}$. DM is estimated, or a volume of approximately $3 \mathrm{~L}$ of $\mathrm{CH}_{4}$. This quantity of methane corresponds to a proportion of $65.6 \% \mathrm{CH}_{4}$. From these results, an extrapolation of the quantities of biogas and methane by 2035 was established (Table 1). This extrapolation is made from the equation of the curve obtained during the co-digestion tests. These tests consisted in establishing the production of biogas by varying the amount of co-substrates.

Table 1. Quantities of biogas and methane estimated by 2035

\begin{tabular}{cccc}
\hline Year & $\begin{array}{c}\text { Total amount of co-substrates } \\
(\text { t.DM })\end{array}$ & Volume of biogas $\left(\mathrm{m}^{3}\right)$ & Volume of $\mathrm{CH}_{4}\left(\mathrm{~m}^{3}\right)$ \\
\hline 2018 & 1853.22 & 36508.00 & 23949.25 \\
2019 & 2449.54 & 48255.00 & 31655.28 \\
2020 & 2470.34 & 48665.00 & 31924.24 \\
2025 & 2811.76 & 55391.00 & 36336.50 \\
2030 & 3435.08 & 67671.00 & 44392.18 \\
2035 & 4158.96 & 81931.00 & 53746.74 \\
\hline
\end{tabular}

Table 1 shows that by 2025, the co-digestion of the fermentable fractions of solid waste and faecal sludge from the city of Sokodé would produce around $36,337 \mathrm{~m}^{3}$ of methane. In 2030 , production would be around $44,392 \mathrm{~m}^{3}$ and in 2035 it would be $53,747 \mathrm{~m}^{3}$. These quantities are quite large and could be used in households and solve the problem of gas stock in the city of Sokodé.

\section{Quantity of energy produced, recoverable and supplied by biogas}

The amount of energy produced by biogas is calculated from the LCV of methane. It is 9.94 $\mathrm{kWh} / \mathrm{m}^{3}$ under normal temperature and pressure conditions [11]. With regard to recoverable energy, it is calculated by admitting $5 \%$ energy loss in order to be sure that the engine is rather overfed than underfed. The results obtained are presented in Table 2.

Table 2. Quantity of energy produced, recoverable and supplied

\begin{tabular}{cccc}
\hline Year & $\begin{array}{c}\text { Total energy produced } \\
(\mathrm{kWh})\end{array}$ & $\begin{array}{c}\text { Recoverable energy } \\
(\mathrm{kWh})\end{array}$ & $\begin{array}{c}\text { Energy supplied by the biogas in } \\
1 \mathrm{~h}\end{array}$ \\
& & & $\begin{array}{c}\mathrm{kWh}) \\
\end{array}$ \\
\hline 2025 & 361190 & 343131 & 40 \\
2030 & 441257 & 419195 & 48 \\
2035 & 534246 & 507534 & 58 \\
\hline
\end{tabular}

Table 2 shows that by 2035, the co-digestion of fermentable solid waste and faecal sludge from the city of Sokodé, would produce $534,246 \mathrm{kWh}$. The recoverable part would be 
$507,534 \mathrm{kWh}$ and the energy supplied is $58 \mathrm{kWh}$. This energy could be used to run an engine and supply the faecal sludge treatment plant in the city of Sokodé. The motor to be chosen must be able to operate between $50 \%$ and $100 \%$ of its nominal load, with an optimum efficiency of around $75 \%$.

\section{Conclusion}

The objective of this work was to assess the amount of energy produced from the biogas obtained from the co-digestion of the fermentable fractions of solid waste and faecal sludge in the town of Sokodé. The results obtained show that the quantity estimated at horizon 2035 is significant and could be used to run an engine and provide lighting for the faecal sludge treatment plant. The pilot tests were carried out on a laboratory scale and in future investigations, it will be a question of large-scale implementation of the technology for producing biogas and converting this biogas into energy. Moreover, this work is part of current research themes on renewable energies and for environmental protection. Thus, in the rest of the work, the assessment of the environmental impacts of this project will be addressed. In fact, it will be a question of making an assessment of the energy and emissions saved by the conversion of biogas into electrical energy, compared to the production of electricity using natural gas will be made. Knowledge of the $\mathrm{CO}_{2}$ emissions saved would be an added value in terms of the project's contribution to reducing $\mathrm{CO}_{2}$ emissions. With the saving of fossil resources, this project will also contribute to the energy independence objectives of the faecal sludge treatment plant in the city of Sokodé.

\section{Acknowledgments}

We are grateful for the Head of the Water and Environmental Sanitation Laboratory and Supervisor of this work, Professor Gnon BABA for funding.

\section{REFERENCES}

1. Samah H. Diagnosis of the energy situation in Togo. Togolese Republic: Ministry of the Environment, Department of Water and Forests; 2015.

2. Tcha-Thom M. Study of a sustainable way of methanization of fruit and slaughter wastes in Togo: Evaluation of the agronomic potential of digestate on the soil of Kara.. INIS; 2019 July, p. 205.

3. Sigot L. Fine purification of biogas for energy recovery in a SOFC-type fuel cell: Adsorption of octamethylcyclotetrasiloxane and hydrogen sulfide. Environment and Society. Lyon: INSA; 2014.

4. Lejeune P. Electrical and thermal recovery of methanization biogas. Paris: EFE training Biomass for energy uses; 2008.

5. Haushalter J. Sizing of a biomass cogeneration. Mulhouse: Wärtsilä; 2007

6. Couturier C. Techniques for producing electricity from biogas and syngas. 2009.

7. Heduit. Methanization of animal droppings. Depollution and energy production. General review of thermics. 1987;26(3):228-235.

8. Ohannessian A. Volatile Organic Silicon Compounds: A brake on energy recovery from biogas. Genesis and Mechanisms of Formation. Lyon: National Institute of Applied Sciences; 2008.. 
9. Akpaki O. Physico-chemical characterization of Attidjin faecal sludge (prefecture of the gulf-togo). Chemistry of Water and the Environment, University of Lomé; 2015, p. 167.

10. Pouech, P. Interest of co-digestion for the recovery of slurry and the treatment of fermentable waste at the scale of a territory. 37th Swine days' Research; Paris. 2005, $39-44$..

11. Couturier C, Berger S, Hérau I. Anaerobic digestion of urban sludge. Toulouse: Water Agency Adour-Garonne; 2001. 